\title{
Emissão de material particulado por misturas ternárias compostas de biodiesel, etanol e óleo vegetal: uma comparação com o óleo diesel convencional
}

\section{Emission of particulate matter from ternary blends consisting of biodiesel, ethanol and vegetable oil: a comparison with conventional diesel}

\author{
José Luiz Bernardo Borges ${ }^{1 *}$; Márcio Turra de Ávila²; Ricardo Ralisch ${ }^{3}$; Murilo \\ Daniel de Melo Innocentini ${ }^{4}$
}

\begin{abstract}
Resumo
O objetivo deste trabalho foi quantificar a emissão de material particulado de misturas ternárias compostas de biodiesel, etanol e óleo vegetal em um motor de ciclo Diesel, tendo como testemunha um motor idêntico funcionando com óleo diesel de petróleo. Para a comparação da emissão dos dois combustíveis, foi realizada a coleta de material particulado proveniente dos escapamentos dos motores com um filtro circular confeccionado de fibra de vidro, que foi acoplado com um flange de aço, no final da tubulação de escape. Os resultados obtidos com a utilização das misturas ternárias de biocombustíveis indicaram uma redução expressiva no nível de material particulado emitido pelo motor em sua carga máxima. Pode-se concluir que a utilização das misturas ternárias, nas condições e métodos de realização do experimento, foi eficiente na redução de emissão de material particulado presente nos gases de exaustão do motor de ciclo Diesel.
\end{abstract}

Palavras-chave: Biocombustíveis, motor de ciclo diesel, emissões

\begin{abstract}
The purpose of this study was to quantify the particulate matter emission from ternary blends comprehending biodiesel, ethanol and vegetable oil in a Diesel cycle engine, and an identical engine working with petrol diesel as control. To compare the fuels' emissions, the particulate matter from the engine's exhaust was collected, using a fiberglass circular filter paper, which was coupled by means of a steel flange at the end of the exhaust pipe. The results with ternary blends showed expressive reduction of particulate matter level exhausted by the engine, in its maximum load. We can conclude that the utilization of ternary blends, with the methods and conditions of this experiment, was efficient to reduce the emission of particulate matter contained in the exhaust gases of Diesel cycle engine.
\end{abstract}

Key words: Biofuels, diesel cycle engine, emissions

${ }^{1}$ Eng $^{\mathrm{o}} \mathrm{Agr}^{\mathrm{o}}$, Prof. Msc. do Dept ${ }^{\circ}$ de Ciências Agrárias e Biológicas da Faculdade Interamericana de Porto Velho/RO, UNIRON, Porto Velho, RO. E-mail: borges-j1@hotmail.com

2 Eng ${ }^{\circ}$ Mecânico, Pesquisador Dr. da Empresa Brasileira de Pesquisa Agropecuária, Embrapa/Soja, Londrina, PR. E-mail: mtavila2003@yahoo.com.br

${ }^{3}$ Eng $^{\circ}$ Agr $^{\circ}$, Prof. Dr. do Dept ${ }^{\circ}$ de Agronomia da Universidade Estadual de Londrina, UEL, Londrina, PR. E-mail: ralisch@uel.br

${ }^{4}$ Eng $^{\mathrm{O}}$ Químico, Prof. Dr. do Curso de Engenharia Química da Universidade de Ribeirão Preto, UNAERP, Ribeirão Preto, SP. E-mail: muriloinnocentini@yahoo.com.br

* Autor para correspondência 


\section{Introdução}

Os compostos de emissão, tanto dos motores a diesel, quanto a gasolina ou combustíveis mistos, podem ser classificados em dois tipos: os que não causam danos à saúde, ou seja, $\mathrm{O}_{2}, \mathrm{CO}_{2}, \mathrm{H}_{2} \mathrm{O}$ e $\mathrm{N}_{2}$; e os que apresentam perigos à saúde, sendo esses subdivididos em compostos cuja emissão está regulamentada, que são: monóxido de carbono $(\mathrm{CO})$, hidrocarbonetos $(\mathrm{HC})$, óxidos de nitrogênio $\left(\mathrm{NO}_{\mathrm{x}}\right)$, óxidos de enxofre $\left(\mathrm{SO}_{\mathrm{x}}\right.$ ) e material particulado (MP); e aqueles que ainda não estão sob regulamentação: aldeídos, amônia, benzeno, cianetos, tolueno e hidrocarbonetos aromáticos polinucleares (HPA) (NEEFT; MAKKEE; MOULIJN, 1996).

O material particulado (MP) produzido por uma máquina diesel consiste, basicamente, de aglomerados de núcleos de carbono e de hidrocarbonetos, $\mathrm{SO}_{3}$ ou ácido sulfúrico e água, adsorvidos ou condensados sobre esses núcleos carbônicos (NEEFT; MAKKEE; MOULIJN, 1996; BRAUN; APPEL; SCHMAL, 2003).

A composição mássica média do material particulado é de 70\% em massa de carbono, 20\% de oxigênio, $3 \%$ de enxofre, $1,5 \%$ de hidrogênio, menos que $1 \%$ de nitrogênio e, aproximadamente, $1 \%$ de elementos traços (NEEFT; MAKKEE; MOULIJN, 1996).

O MP é o poluente atmosférico mais consistentemente associado a efeitos adversos à saúde humana. Sua toxicidade depende, basicamente, de sua composição e de seu diâmetro aerodinâmico. Diversos estudos têm relacionado a exposição contínua aos níveis ambientais de material particulado com a redução da expectativa de vida (LIPFERT, 1984; DOCKERY; POPE, 1994; ABBEY et al., 1999).

Os efeitos crônicos também têm sido demonstrados a partir da detecção de alterações estruturais dos pulmões de indivíduos que habitam regiões com elevadas concentrações de MP. A primeira demonstração clara de que os elevados níveis desse poluente promovem alterações inflamatórias difusas do trato respiratório em humanos veio de estudos de Souza et al. (1998), nos quais foram detectados hiperplasia muco-secretora, remodelamento com fibrose das pequenas vias aéreas e lesão da região centro acinar de jovens falecidos por causas externas na região metropolitana de São Paulo. Neste mesmo estudo, as lesões observadas estavam em íntima relação anatômica com focos de deposição e retenção de material carbonáceo (antracose), sugerindo uma relação de causa e efeito.

Etanol, óleo vegetal e biodiesel são todos derivados da biomassa e, ao contrário do petróleo, são combustíveis renováveis. Entre estes combustíveis, o álcool etílico hidratado combustível (AEHC) se apresenta como um interessante combustível alternativo ao óleo diesel para reduzir as emissões de poluentes. Isso porque o etanol contém oxigênio na sua molécula, e é um combustível extremamente volátil. Essas características são, geralmente, favoráveis para uma boa combustão (PÉREZ et al., 2006; FELICI et al., 2009).

O uso de etanol como combustível é defendido em função da redução nas emissões de gases responsáveis pelo efeito estufa ao substituir os combustíveis fósseis. Macedo, Seabra e Silva (2008) analisaram o balanço de energia consumida na produção e processamento (óleo diesel, vapor, agrotóxicos, etc.) da cana-de-açúcar, comparativamente à energia proporcionada pelo uso do etanol e pelo bagaço da cana. A relação entre a energia renovável produzida (levando-se em consideração o etanol e o bagaço de cana-de-açúcar) e a energia fóssil consumida na produção do biocombustível variou de 8,3 a 10,2, isto é, a cada unidade de energia fóssil gasta no ciclo de produção do etanol, são obtidas entre 8,3 a 10,2 unidades de energia renovável.

Segundo Schumacher et al. (2001), o etanol, praticamente, não possui enxofre em sua composição, logo, o seu uso não contribui para a emissão de SOx, além do que a sua menor complexidade molecular possibilita uma combustão com baixíssima formação de partículas de carbono, o que resulta em uma 
emissão desprezível de MP.

Outro fator de estímulo ao mercado de álcool é a possibilidade de adição de etanol ao diesel: testes demostraram que a utilização de mistura de 3\% de etanol com $97 \%$ de diesel pode ser adotada em qualquer motor sem ocasionar problemas, reduzindo as emissões de material particulado e outros poluentes (HE et al., 1994; GELLER et al., 2004).

No Brasil, estudos com a mistura álcool/diesel vêm sendo realizados desde 1984, quando foi verificado que determinadas porcentagens de óleo diesel com álcool anidro eram viáveis, pois não causavam perda de eficiência do motor ou aumento do consumo de combustível, e geravam redução na emissão de particulados. Desta maneira, trabalhos de pesquisa e testes de campo têm sido realizados para implantação de um programa de adição de etanol à matriz energética do diesel (ECONOMY \& ENERGY, 2001).

O biodiesel apresenta crescimento acelerado no mercado nacional de biocombustíveis líquidos. Porém, ao contrário do etanol, que encontrou na canade-açúcar sua matéria-prima ideal, este ainda está em estágio de intensa pesquisa e desenvolvimento (PNA, 2005). Entretanto, diversos são os trabalhos que apontam vantagem ambiental a favor do biodiesel em relação ao diesel convencional, fato que o coloca na linha de frente dos sucedâneos ao petrodiesel.

Muñoz, Moreno e Morea (2004) testaram misturas de éster metílico de girassol e diesel (B25, B50, B75 e B100) em um motor Diesel automotivo para determinação dos níveis de emissão de poluentes. Nos testes realizados, a emissão de hidrocarbonetos com as misturas de biodiesel foi menor em relação ao diesel, especialmente, em condições de alta exigência de potência durante a operação. A concentração de $\mathrm{NO}_{\mathrm{x}}$ com biodiesel puro, entretanto, foi sempre maior do que com o diesel. Contudo, a reduções do grau de enegrecimento e da emissão específica de material particulado medido são representativas e favoráveis ao uso do biodiesel, o que, em parte, é explicado pela ausência de enxofre no biodiesel. Em determinada etapa do funcionamento do motor, o enxofre compartilha o oxigênio disponível na fase tardia da combustão com o carbono resultante da queima parcial, aumentando a produção de material particulado.

Nesse contexto, o objetivo deste trabalho foi quantificar a emissão de material particulado de misturas ternárias compostas de etanol, biodiesel e óleo vegetal em um motor de ciclo Diesel, tendo como testemunha um motor idêntico funcionando com diesel convencional.

\section{Material e Métodos}

Os testes envolvendo misturas de combustíveis alternativos foram realizados no Laboratório de Engenharia Agrícola do Centro Nacional de Pesquisa de Soja (Embrapa Soja), em Londrina - PR, onde estão alocados os motores estacionários e o gerador de eletricidade empregados na experimentação.

\section{Descrição dos motores utilizados}

Para os testes, foram utilizados dois motores estacionários de ciclo Diesel a 4 tempos, da marca Toyama (Figura 1), modelo T70f, arrefecidos a ar, com injeção direta e 6 HP de potência nominal, sendo que um deles foi abastecido somente com óleo diesel, e o outro, com a mistura ternária que continha óleo vegetal, biodiesel e etanol; dessa forma, cada motor pode ser avaliado individualmente, de acordo com o combustível empregado. As principais especificações técnicas e medidas dos motores são descritas na Tabela 1.

Para a realização de testes procurando simular, concretamente, as exigências mecânicas a que um motor desse tipo é submetido, foi necessário imprimir uma determinada carga aos motores através do uso de um gerador de energia elétrica e de lâmpadas incandescentes. 
Figura 1. Motor Toyama T70f.

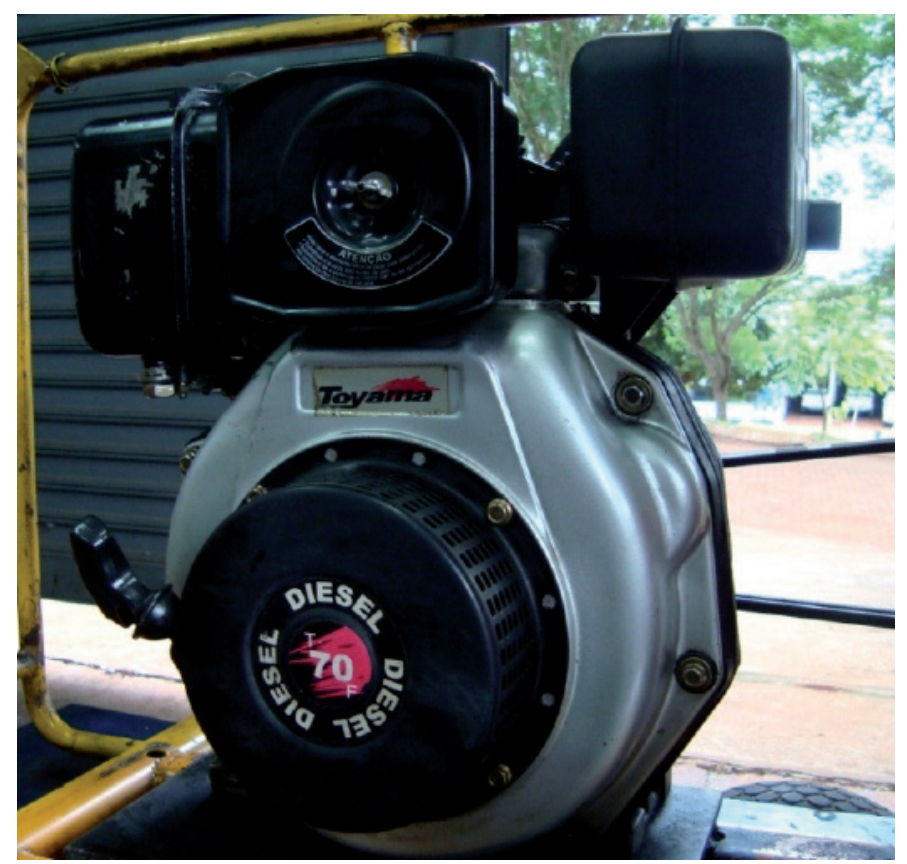

Tabela 1. Especificações técnicas e medidas do motor Toyama T70f.

\begin{tabular}{|c|c|}
\hline Item & Especificação técnica \\
\hline Modelo & T 70f \\
\hline Tipo & Monocilíndrico, 4 tempos \\
\hline Arrefecimento & $\mathrm{Ar}$ \\
\hline Cilindrada (1) & 0,296 \\
\hline Rotação nominal (rpm) & 3.600 \\
\hline Potência nominal (HP) & 5,4 \\
\hline Velocidade média do pistão (m/s) & 7,44 \\
\hline Pressão efetiva média (kgf/cm2) & 5,52 \\
\hline Relação de consumo de combustível (g/HP.h) & $<215$ \\
\hline Relação de consumo de óleolubrificante (g/HP.h) & $<3$ \\
\hline Capacidade do tanque de combustível (1) & 3,5 \\
\hline Sentido do eixo de rotação & Horário, visto do volante \\
\hline Tipo e lubrificação & Bomba de óleo \\
\hline Tipo de partida & Manual retrátil \\
\hline Peso líquido (kg) & 33 \\
\hline
\end{tabular}

\section{Aplicação de carga aos motores}

No intuito de fixar carga aos motores, foi empregado um gerador elétrico da marca Bambozzi (Figura 2), de 10 kVA, com rotação nominal de $1800 \mathrm{rpm}$; portanto, passível de ser utilizado com o motor supracitado, que possuía rotação nominal de 3000 a 3600 rpm. Este gerador serviu como fonte de energia elétrica para um conjunto de lâmpadas ligadas em série, cuja 
potência requerida foi produzida e transmitida ao gerador pelo trabalho mecânico do motor Diesel.

Figura 2. Gerador a diesel de 10kVA.

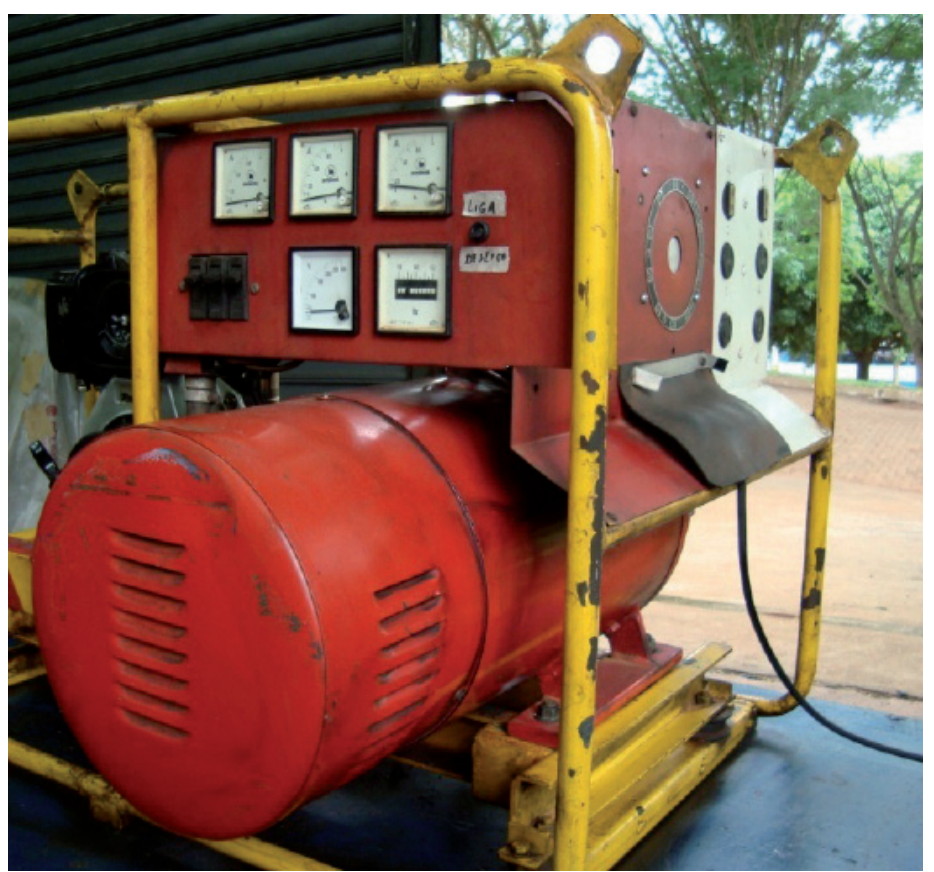

A intenção foi de que o motor funcionasse com pelo menos $70 \%$ de sua potência total, para simulação de operação em torno da faixa ótima de utilização. Essa foi a razão para o emprego de um conjunto de 18 lâmpadas de 150 W.

Desta forma as 18 lâmpadas de 150 Watts cada uma foram instaladas no conjunto, o que determinou uma carga elétrica de 2700 Watts. Como o motor possuía 6 HP de potência nominal ( $1 \mathrm{HP}=745,7 \mathrm{~W}$ ), este foi suficientemente capaz de alimentar as lâmpadas.

\section{Seleção das misturas ternárias de combustiveis}

Dentre todas as misturas estáveis, conforme descritas na tabela 2, três delas foram selecionadas para as avaliações primárias do experimento, tendo como base as características físico-químicas estabelecidas pela ANP para o óleo diesel mineral, como, por exemplo, viscosidade, índice de cetano e poder calorífico (Tabela 3). As três propriedades das misturas ternárias (viscosidade cinemática, cetanagem e poder calorífico), contidas na Tabela 3, foram obtidas através de correlações matemáticas e não por testes experimentais.

Além disso, deu-se preferência para misturas com maior quantidade possível de etanol, visto o menor preço deste combustível oxigenado no mercado interno, objetivando sempre a obter um custo final menor que o do diesel convencional. 
Tabela 2. Comparação entre as amostras com 3 substâncias miscíveis $\left(24^{\circ}-26^{\circ} \mathrm{C}\right)$.

\begin{tabular}{lcccc}
\hline $\begin{array}{l}\text { Resultado } \\
\text { (miscibilidade) }\end{array}$ & $\begin{array}{c}\text { \% Biodiesel (B) } \\
\text { (massa) }\end{array}$ & $\begin{array}{c}\text { \% Etanol Hidratado (EH) } \\
\text { (massa) }\end{array}$ & $\begin{array}{c}\text { \% Óleo Vegetal (OV) } \\
\text { (massa) }\end{array}$ & $\begin{array}{c}\text { Composição } \\
\text { (B : EH : OV) }\end{array}$ \\
\hline Sim & 50 & 40 & 10 & $50: 40: 10^{*}$ \\
Sim & 50 & 10 & 40 & $50: 10: 40$ \\
Sim & 60 & 30 & 10 & $60: 30: 10 *$ \\
Sim & 60 & 20 & 20 & $60: 20: 20^{*}$ \\
Sim & 60 & 10 & 30 & $60: 10: 30$ \\
Sim & 70 & 20 & 10 & $70: 20: 10$ \\
Sim & 70 & 10 & 20 & $70: 10: 20$ \\
Sim & 80 & 10 & 10 & $80: 10: 10$ \\
\hline
\end{tabular}

*Misturas empregadas no experimento.

Tabela 3. Propriedades físico-químicas dos combustíveis, em função da composição da mistura ternária.

\begin{tabular}{lccc}
\hline B : EH : OV & Viscosidade (cSt) & Índice de cetano & Poder Calorífico (kJ/kg) \\
\hline $60: 20: 20$ & 4,1 & 39,9 & 34.733 \\
$60: 30: 10$ & 3,0 & 36,5 & 35.707 \\
$50: 40: 10$ & 2,6 & 31,8 & 37.032 \\
Óleo diesel & $1,6-6,0$ & 47,64 & 45.000 \\
\hline
\end{tabular}

*Kwanchareon, Luengnaruemitchai e Jai-In, 2007.

B: Biodiesel; EH: Etanol Hidratado; OV:Óleo Vegetal.

Assim sendo, as três misturas selecionadas para as avaliações primárias foram as seguintes:

- Mistura 1: 60\% de biodiesel (B), 20\% de etanol hidratado (EH) e $20 \%$ de óleo vegetal refinado $(\mathrm{OV})$ (em volume);

- Mistura 2: 60\% de biodiesel (B), 30\% de etanol hidratado $(\mathrm{EH})$ e $10 \%$ de óleo vegetal refinado $(\mathrm{OV})$ (em volume);

- Mistura 3: 50\% de biodiesel (B), 40\% de etanol hidratado $(\mathrm{EH})$ e $10 \%$ de óleo vegetal refinado $(\mathrm{OV})$ (em volume).

O biodiesel empregado no experimento foi produzido na empresa BIOPAR, localizada em Rolândia-PR, a qual possui certificação da ANP para a produção e comercialização do mesmo. A matéria-prima utilizada na produção desse, foi uma mistura de óleo de soja (Glycine max L.) e sebo bovino.

O óleo vegetal que compôs as misturas foi do tipo refinado, também tendo como matériaprima a soja (Glycine Max L.), proveniente da cooperativa agroindustrial COCAMAR, localizada em Maringá-PR.

O etanol foi proveniente da Usina Nova América-S.A., produzido a partir da cana-deaçúcar (Saccharum spp.) e disposto na sua forma hidratada (7\% de água).

A Tabela 3 apresenta dados relacionados às propriedades físico-químicas dos combustíveis utilizados nos ensaios, numa temperatura variando de 24 a $26^{\circ} \mathrm{C}$.

\section{Análise dos gases de exaustão}

Foi realizada a coleta de material particulado (MP) proveniente dos escapamentos dos motores por meio de filtro circular, com diâmetro de $0,05 \mathrm{~m}$, confeccionado a partir de fibra de vidro (Figura 3), material este adquirido da empresa 
Energética-Qualidade do Ar - RJ, especializada em materiais para análises desse tipo.

Esses filtros foram secados previamente em estufa a $105{ }^{\circ} \mathrm{C}$ para eliminação da umidade existente. Após a secagem, os filtros foram pesados em balança digital de precisão para, finalmente, serem instalados na extremidade final da tubulação de escape, onde permaneceram por 2, 5, 8 e 10 minutos, com a finalidade de reterem o material particulado exaurido pelo motor. Essa fixação ocorreu por meio de um suporte de aço (flange), que foi ali adaptado para tal finalidade (Figuras 4 e 5).

Figura 3. Filtros de fibra de vidro empregados na coleta do MP. (a): antes da coleta e (b): após 5 minutos de coleta.

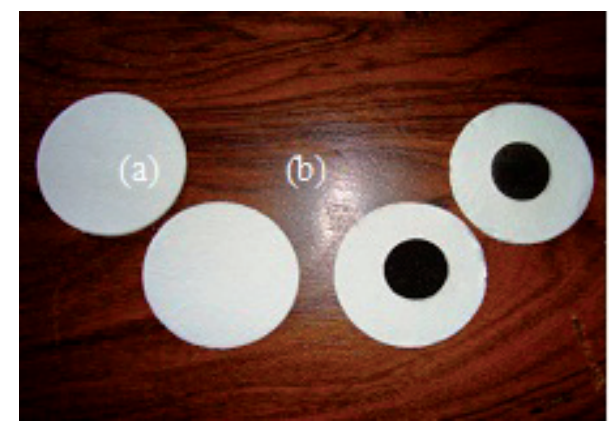

Figura 4. Tubulação de aço acoplada ao escapamento para coleta de MP.

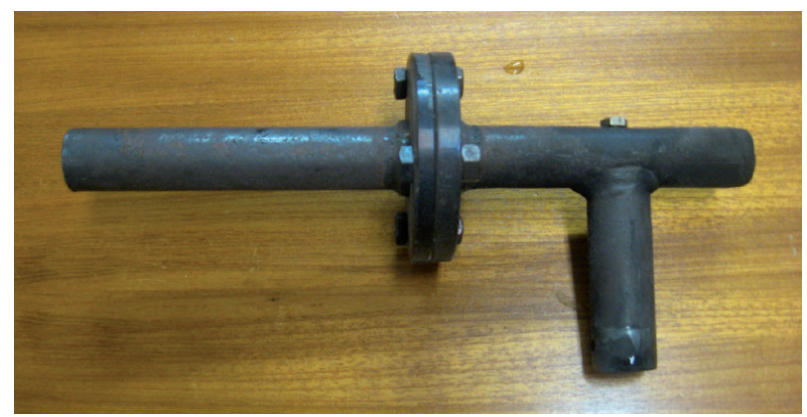

Figura 5. Detalhe do local onde foi inserido o filtro para coleta do MP.

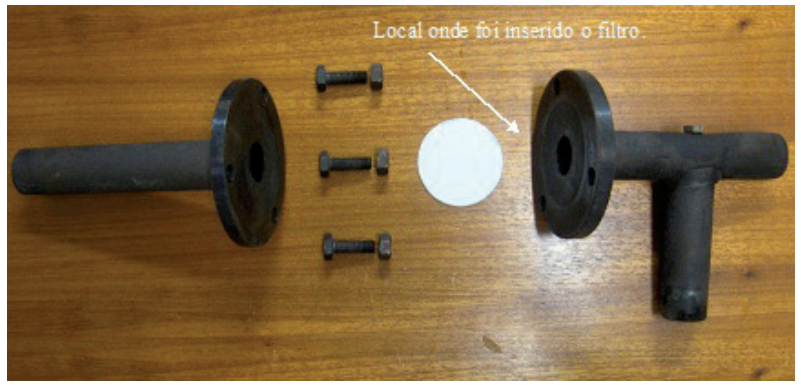

Para a determinação do tempo ideal para coleta, foram realizados testes de retenção variados, com os quais se notou uma diferença expressiva na quantidade de MP coletado nos filtros expostos por 2 e 5 minutos, com resultados mais significativos no maior tempo de exposição. Já com 8 e 10 minutos de exposição, não se verificou diferença entre o material retido nos mesmos e no filtro exposto por 5 minutos; assim sendo, adotou-se, para os testes, o tempo padrão de 5 minutos de permanência.

Após os 5 minutos de coleta do material, os papéis-filtro foram novamente secados e, em seguida, levados para a balança de precisão, onde foi aferida a quantidade, em massa, de particulados expelidos pelos motores.

\section{Resultados e Discussão}

Os resultados obtidos com a utilização das misturas ternárias de biocombustíveis indicaram uma redução expressiva no nível de material particulado emitido pelo motor em sua carga máxima, comportamento este proveniente da substituição de um combustível de cadeia carbônica longa (óleo diesel), em média 13 carbonos, e alto ponto de ebulição (de 190 a 330 oC), por uma mistura de combustíveis contendo etanol, de cadeia mais simples e menor temperatura de ebulição.

Os valores obtidos no experimento estão apresentados na Figura 6, na forma de massa específica do material retido, num intervalo de 5 minutos de coleta, utilizando filtro de fibra de vidro. 
Figura 6. Emissão de MP, durante 5 minutos de coleta, em função da carga aplicada e do combustível. B: Biodiesel; EH: Etanol Hidratado; OV: Óleo Vegetal.

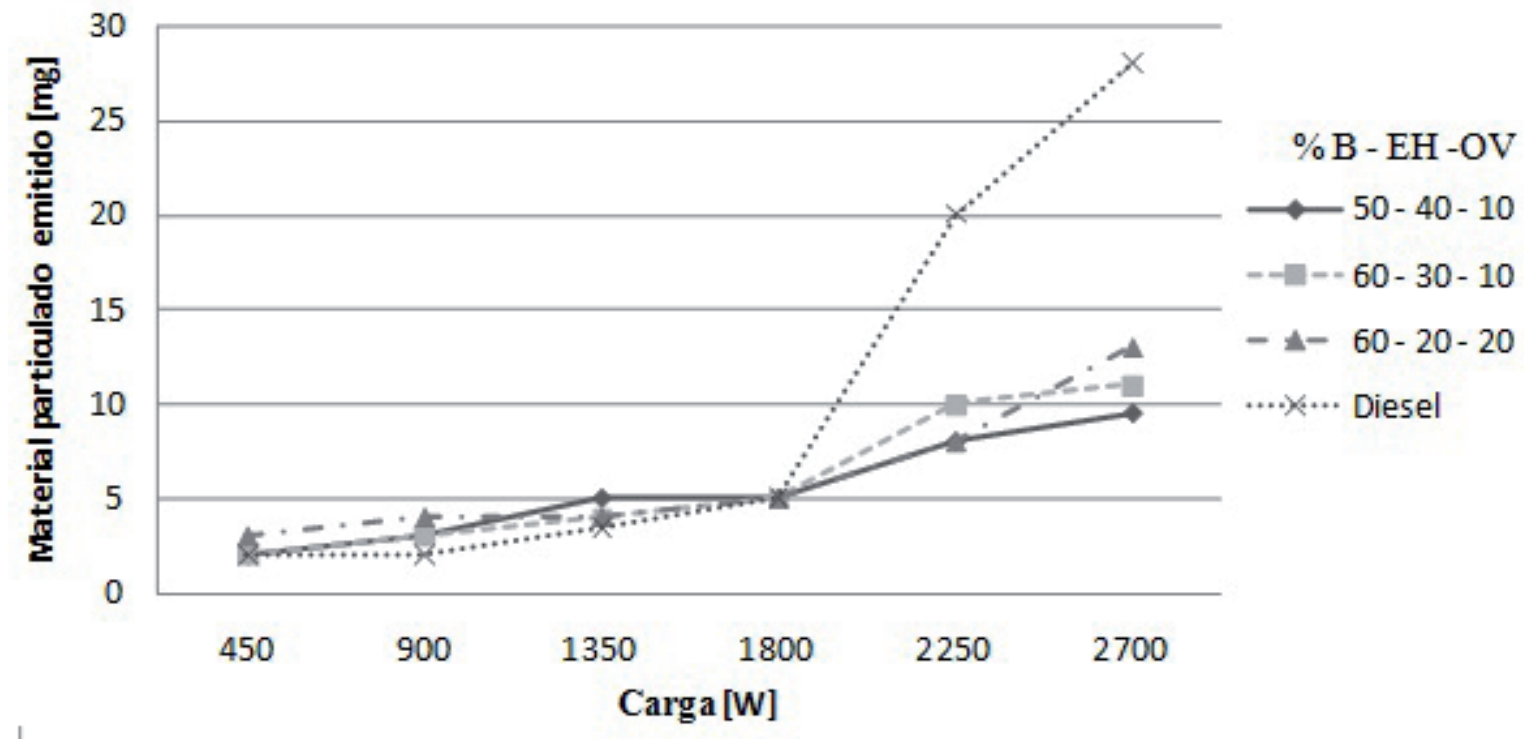

Nota-se que, quando a carga demandada pelo gerador não ultrapassa $1800 \mathrm{~W}$, a emissão de MP entre os combustíveis é semelhante; porém, na medida que se eleva a carga até $2700 \mathrm{~W}$, em que maior volume de combustível é pulverizado na câmara de combustão, a quantidade de MP emitida pelo diesel é bastante superior a todas as misturas, sendo $28 \mathrm{mg}$ para o diesel, enquanto as misturas ternárias variam de 10 a 13 mg para a carga máxima. Observa-se, também, que o aumento de etanol na mistura ternária favorece a queda na emissão de MP, fato que, segundo Dietrich e Bindel (1989) se explica pela capacidade do etanol em proporcionar uma combustão mais completa, implicando em redução no teor de carbono não queimado, corroborando os resultados encontrados no experimento.

Tem sido amplamente apresentado na literatura que ao se adicionar etanol ao diesel, o principal benefício é a redução de fuligem e material particulado, seguido pela diminuição de CO. Ajav, Singh e Bhattacharya (1999) mostraram que, ao incrementar a porcentagem de etanol na mistura com diesel, as emissões de MP foram reduzidas. Suppes (2000) analisou os resultados experimentais de diferentes autores, concluindo que se pode falar efetivamente de redução do material particulado quando se adiciona etanol ao diesel. A redução dos particulados também é destacada na ampla revisão bibliográfica feita por Hansen, Zhang e Lyne (2005).

Outro composto presente na mistura, que também foi responsável pela queda na emissão de particulados, é o biodiesel.

Diversos autores têm demonstrado a eficiência deste na redução dos particulados totais do motor. Misturas de biodiesel de girassol/diesel foram utilizadas por Muñoz, Moreno e Morea (2004), para determinação dos níveis de emissão de poluentes, e os autores observaram redução bastante representativa na emissão específica de MP (algo favorável ao uso do biodiesel), o que, em parte, foi explicado pela ausência de enxofre no biocombustível.

O enxofre compartilha o oxigênio disponível na fase tardia da combustão com o carbono resultante da queima parcial, em algumas condições de funcionamento do motor, aumentando a produção de material particulado (MUÑOZ; MORENO; MOREA, 2004; SHARP et al., 2000). 


\section{Conclusões}

Pelos resultados obtidos com o emprego das misturas ternárias de biocombustíveis, pode-se concluir que:

A utilização das misturas ternárias, nas condições e métodos de realização desse experimento, é eficiente na redução de emissão de material particulado presente nos gases de exaustão do motor de ciclo Diesel. O óleo diesel é o combustível responsável pela maior quantidade de material particulado emitido, enquanto a mistura $50-40-$ 10 lança o menor teor de material particulado para a atmosfera.

\section{Agradecimentos}

À Universidade Estadual de Londrina e à Embrapa Soja pelos suportes técnico e científico oferecidos durante a realização deste trabalho.

À CAPES, pelo apoio financeiro concedido durante todas as fases deste trabalho.

\section{Referências}

ABBEY, D. E.; NISHINO, N.; MCDONNELL, W. F.; BURCHETTE, R. J.; KNUTSEN, S. F.; BEESON, W. L.; YANG, J. X. Long-term inhalable particles and other air pollutants related to mortality in nonsmokers. American Journal of Respiratory and Critical Care Medicine, New York, USA, v. 2, n. 159, p. 373-382, 1999.

AJAV, E. A.; SINGH, B.; BHATTACHARYA, T. K. Experimental study of some performance parameters of a constant speed stationary diesel engine using ethanoldiesel blends as fuel. Biomass and Bioenergy, London, UK, v. 17, n. 4, p. 357-365, 1999.

BRAUN, S.; APPEL, L. G.; SCHMAL, M. A poluição gerada por máquinas de combustão interna movidas a diesel - a questão dos particulados. Estratégias atuais para a redução e controle das emissões e tendências futuras. Química Nova, Brasília, v. 27, n. 3, p. 472-482, 2003.

DIETRICH, W.; BINDEL, H. W. H. O desenvolvimento da "injeção piloto" para uso de álcoois em motores ciclo Diesel. In: SIMPÓSIO DE ENGENHARIA AUTOMOTIVA, 1.; ENCONTRO DOS CENTROS DE APOIO TECNOLÓGICO, 11., 1989, Brasília. Anais...
Brasília: Editora UNB, 1989. p. 515-533.

DOCKERY, D. W.; POPE, C. A. III. Acute respiratory effects of particulate air pollution. Annual Review on Public Health, Palo Alto, USA, v. 15, p. 107-132, 1994.

ECONOMY \& ENERGY. Progressos na matriz energética e de emissões de gases causadores do efeito estufa. Brasília, n. 25, mar./abr. 2001. Disponível em: $<$ http;//www.ecen.com>. Acesso em: 15 maio 2008.

FELICI, P. H. N.; BORGES, J. L. B.; RALISCH, R.; GAZZONI, D. L.; ÁVILA, M. T. Mini-usina de craqueamento térmico de óleos vegetais para pequenos produtores: avaliação operacional de um protótipo. Semina: Ciências Agrárias, Londrina, v. 30, n. 4, p. 779792, 2009.

GELLER, H.; SCHAEFFER, R.; SKLO, A.; TOLMASQUIM, M. Policies for advancing energy efficiency and renewable energy use in Brazil, Energy Policy, London, UK, v. 32, n. 12, p. 1437-1450, 2004.

HANSEN, A. C.; ZHANG, Q.; LYNE, P. W. L. Ethanoldiesel fuel blends a review. Bioresource Technology, New York, USA, v. 96, n. 2, p. 227-285; 2005.

HE, B. Q.; SHUAI, S. J.; WANG, J. X.; HE, H. The effect of ethanol blended diesel fuels on emissions from a diesel engine. Atmospheric Environment, Earlham, UK, v. 37, n. 35, p. 4965-4971, 1994.

KWANCHAREON， P.; LUENGNARUEMITCHAI, A.; JAI-IN, S. Solubility of a diesel-biodiesel-ethanol blend, its fuel properties, and its emission characteristics from diesel engine. Fuel, Amsterdan, NED, v. 86, n. 7, p. 1053-1061, 2007.

LIPFERT, F. W. Air pollution and mortality: specification searches using SMSA-based data. Journal of Environmental and Economy Management, Raleigh, USA, v. 11, p. 208-243, 1984.

MACEDO, I. C.; SEABRA, J. E. A.; SILVA, J. E. A. R. Green house gases emissions in the production and use of ethanol from sugarcane in Brazil: the 2005/2006 averages and a prediction for 2020. Biomass and Bioenergy, London, UK, v. 32, n. 7, p. 582-595, 2008.

MUÑOZ, M.; MORENO, F.; MOREA, J. Emissions of an automobile diesel engine fueled with sunflower methyl ester. Transactions of the ASAE, St. Joseph, USA, v. 47, n. 1, p. 5-11, 2004.

NEEFT, J. P. A.; MAKKEE, M.; MOULIJN, J. A. Diesel particulate emission control. Fuel Processing Technology, Hershey, USA, v. 47, n. 1, p. 1-69, 1996.

PÉREZ, E. P.; CARVALHO JUNIOR, J. A.; CARROCCI, L. R. Substituição do óleo diesel por álcool etílico hidratado na queima direta: uma comparação. 
In: CONGRESSO INTERNACIONAL SOBRE GERAÇÃO DISTRIBUIIDA E ENERGIA NO MEIO RURAL, AGRENER GD 2006, 6., 2006, Campinas. Anais.... Campinas: NIPE - Núcleo Interdisciplinar de Planejamento Energético, 2006. v. 1, p. 01-09.

PLANO NACIONAL DE AGROENERGIA - PNA. Ministério da Agricultura Pecuária e Abastecimento, Secretaria de Produção e Agroenergia. Brasília: Embrapa Informação Tecnológica, 2005. 1, 118 p. (Caderno, n. 1).

SCHUMACHER, L. G.; MARSHALL, W.; KRAHL, J.; WETHEREL, W. B.; GRABOWSKI, M. S. Biodiesel emissions data from series 60 DDC Engines. Transactions of the ASAE, St. Joseph, USA, v. 44, n. 6, p. 1465-1468, 2001.

SHARP, C. A.; HOWELL, S. A.; JOBE, J. The effect of biodiesel fuels on transient emissions from modern diesel engines. Part 1, Regulated emissions and performance, SAE Technology Paper Series, Warrendale, USA, n. 1, 2000.

SOUZA, M. B.; SALDIVA, P. H.; POPE, C. A.; CAPELOZZI, V. L. Respiratory changes due to longterm exposure to urban levels of air pollution: a histopathologic study in humans. Chest, Northbrook, USA, v. 5, n. 113, p. 1312-1318, 1998.

SUPPES, G. J. Past mistakes and future opportunities of ethanol in diesel. Bioenergy, Buffalo, oct. 2000. 